\title{
Evaluation of Agglomeration Mechanisms of Non-metallic Inclusions and Cluster Characteristics Produced by Ti/Al Complex Deoxidation in Fe-10mass\% Ni Alloy
}

\author{
Changji XUAN, ${ }^{*}$ Andrey Vladimirovich KARASEV and Pär Göran JÖNSSON \\ KTH Royal Institute of Technology, Department of Materials Science and Engineering, Brinellvägen 23, Stockholm, SE-100 44 \\ Sweden.
}

(Received on January 15, 2016; accepted on April 1, 2016; J-STAGE Advance published date: June 7, 2016)

\begin{abstract}
The characteristics of non-metallic single inclusions and clusters formed in a Fe-10mass\% Ni alloy deoxidized with $\mathrm{Ti}, \mathrm{Al}$ and Ti/Al were investigated. Laboratory experiments were performed, and samples were taken after deoxidation. The composition, number and size of the single inclusions and clusters in the samples were determined using SEM in combination with EDX. The agglomeration mechanism and collision rates of inclusions and clusters were considered in the $\mathrm{Al}$ and Ti/Al deoxidation experiments. The obtained results showed that the number and average size of clusters in all samples of the complex Ti/Al experiment are drastically smaller than those in the Al experiment. The Brownian, Stokes ' and turbulent collisions between particle-particle in clusters, particle-cluster and cluster-cluster were evaluated to determine the cluster formation in the different deoxidation experiments depending on the holding time.
\end{abstract}

KEY WORDS: Ti/Al deoxidation; non-metallic inclusions; cluster; agglomeration; electrolytic extraction; collision rate.

\section{Introduction}

The agglomeration of oxide inclusions, which forms during deoxidation of liquid steel, has negative effects on the casting process (nozzle clogging) and the mechanical properties of the final steel product. Hence, studies of the agglomeration behavior of oxide inclusions are important to obtain information on how to control the cluster formation during steel production.

It is well known that the aluminium is one deoxidant, which is commonly used in the production of different steel grades. However, pure $\mathrm{Al}_{2} \mathrm{O}_{3}$ inclusions, which are precipitated after $\mathrm{Al}$ deoxidation of liquid steel, easily agglomerate into harmful clusters. Therefore, some studies have focused on the control of composition and morphology of single inclusions and clusters in various experiments with following complex $\mathrm{Al}$ deoxidations: i) an addition of $\mathrm{Al}$ followed by an addition of $\mathrm{Ti}^{1-4)}$ ii) an addition of $\mathrm{Al}$ and $\mathrm{Ti}$ at the same time ${ }^{1,5)}$ and iii) a pre-deoxidation by Ti followed by an addition of $\mathrm{Al}^{\left.5,{ }^{5}\right)}$ Moreover, for the $\mathrm{Fe}-\mathrm{Ti}-\mathrm{Al}-\mathrm{O}$ system, several results on the stability phase diagram for equilibrium precipitation predictions have been published. ${ }^{7-10)}$ However, all these studies do not clarify in detail the effect of a Ti pre-deoxidation on the formation of clusters and their characteristics.

In the present work, the agglomeration behavior of non-

\footnotetext{
* Corresponding author: E-mail: changji@kth.se

DOI: http://dx.doi.org/10.2355/isijinternational.ISIJINT-2016-030
}

metallic inclusions produced by $\mathrm{Ti}, \mathrm{Al}$ and $\mathrm{Ti} / \mathrm{Al}$ deoxidations in an Fe-10mass\% Ni alloy at a temperature of $1873 \mathrm{~K}$ have been studied. Both Ti and Al deoxidation experiments were performed as the reference trials. Thereafter, the cluster characteristics and agglomeration mechanism of cluster formation in the $\mathrm{Al}$ and $\mathrm{Ti} / \mathrm{Al}$ deoxidation experiments have been determined using SEM in combination with EDX.

\section{Experiment}

\subsection{Sample Making}

Deoxidation experiments were carried out by charging $\mathrm{Fe}-10 \mathrm{mass} \% \mathrm{Ni}$ alloys $(\sim 160 \mathrm{~g})$ in a high-frequency induction furnace under a protection of an $\mathrm{Ar}$ atmosphere. In order to avoid induction stirring of melt, which can cause an unwanted fluid flow, a graphite susceptor (wall thickness is equal to $10 \mathrm{~mm}$ ) was installed between the crucible and induction coil. High purity $\mathrm{Al}_{2} \mathrm{O}_{3}$ crucibles were used for all deoxidation experiments. After melting and holding during 20 min at $1873 \mathrm{~K}$, the composition of the melt alloy became homogeneous. Three deoxidation experiments were carried out by addition of $\mathrm{Ti}, \mathrm{Al}$ and $\mathrm{Ti} / \mathrm{Al}$. In the $\mathrm{Ti}$ deoxidation experiment (Exp. 1), the melt was deoxidized by an addition of 0.03 mass $\% \mathrm{Ti}$ and then mechanically stirred for 10 $\mathrm{S}$ with an $\mathrm{Al}_{2} \mathrm{O}_{3}$ rod. Afterwards, samples were taken from the melt by using a quartz tube $(\varnothing 6 \mathrm{~mm})$ after holding times of 1 and 5 min (samples 1QT1 and 1QT5) and these were quenched in water. In the $\mathrm{Al}$ deoxidation experiment (Exp. 2), the procedures were the same as that for the Ti 
deoxidation case. After taking the samples after holding times of 1 and $5 \mathrm{~min}$ (samples 2QT1 and 2QT5), the melt in the crucible after a 10 min holding time at $1873 \mathrm{~K}$ was cooled down in the furnace to a temperature of $1473 \mathrm{~K}$. Thereafter, the solidified metal in the crucible (sample 2IC) was quenched by water. The 2IC sample was cut off from a central vertical slice of the obtained ingot for analysis. In the Ti/Al complex deoxidation experiment (Exp. 3), the melt was heated to $1873 \mathrm{~K}$. Then, it was firstly deoxidized by adding $\mathrm{Ti}(=0.03 \%)$, followed by a $10 \mathrm{~s}$ stirring using an alumina rod. After a holding time of $1 \mathrm{~min}, \mathrm{Al}(=0.06 \%)$ was added and then the melt was stirred mechanically for 10 s. Afterwards, samplings were made after holding times of 1, 5 and 10 min (3QT1, 3QT5 and 3QT10). Then, the melt in the crucible was cooled in the furnace up to $1473 \mathrm{~K}$ and quenched in water. A small piece of the 3IC sample was cut off from the obtained ingot. The main conditions in different deoxidation experiments are summarized in Table 1.

\subsection{Investigation of Inclusions}

The characteristics of non-metallic single inclusions (NMSI) and clusters were analyzed in the metal specimens. The metal specimens were first dissolved by using the potentiostatic electrolytic extraction (EE) method. A $10 \%$ AA solution $(10 \mathrm{v} / \mathrm{v} \%$ acetylacetone $-1 \mathrm{w} / \mathrm{v} \%$ tetramethylammonium chloride - methanol) was used as electrolyte. The extraction conditions were the following: a 3-4 V voltage, a $\sim 60 \mathrm{~mA}$ current and a 1000 coulomb charge. The dissolved weight of the metal was about $0.2 \mathrm{~g}$. After the EE, the polycarbonate (PC) membrane film filter

Table 1. Main conditions in $\mathrm{Ti}, \mathrm{Al}$ and $\mathrm{Ti} / \mathrm{Al}$ deoxidation experiments.

\begin{tabular}{|c|c|c|c|c|c|}
\hline $\begin{array}{l}\text { Exp. } \\
\text { No. }\end{array}$ & Deoxidation & $\begin{array}{c}\text { First } \\
\text { addition } \\
{[\mathrm{mass} \%]}\end{array}$ & $\begin{array}{l}\text { Second } \\
\text { addition } \\
{[\operatorname{mass} \%]}\end{array}$ & Sampling & $\begin{array}{c}\text { Holding } \\
\text { time } \\
\text { [min] }\end{array}$ \\
\hline \multirow[t]{2}{*}{1} & $\mathrm{Ti}$ & $0.03 \% \mathrm{Ti}$ & - & 1QT1 & 1 \\
\hline & & & & 1QT5 & 5 \\
\hline \multirow[t]{3}{*}{2} & $\mathrm{Al}$ & $0.06 \% \mathrm{Al}$ & - & 2QT1 & 1 \\
\hline & & & & 2QT5 & 5 \\
\hline & & & & $2 \mathrm{IC} 15$ & 15 \\
\hline \multirow[t]{4}{*}{3} & $\mathrm{Ti} / \mathrm{Al}$ & $0.03 \% \mathrm{Ti}$ & $0.06 \% \mathrm{Al}$ & 3QT1 & 1 \\
\hline & & & & 3QT5 & 5 \\
\hline & & & & 3QT10 & 10 \\
\hline & & & & $3 \mathrm{IC} 15$ & 15 \\
\hline
\end{tabular}

with an open pore size 0.4 or $0.05 \mu \mathrm{m}$ was used for filtration and collection of undissolved single inclusions and clusters. Afterwards, the inclusions on the film filters were investigated by using a scanning electron microscope (SEM) at magnifications of $\times 1000$ and $\times 1500$ to determine the particle size distribution. The observed inclusion number in each deoxidation is in the range between 200 and 300. In this study, this method is called as three dimensional (3D) investigations because the NMSI and clusters are extracted completely from the metal volume. Therefore, they can be observed in their natural form and not in a section.

The diameter of single inclusions and maximum length, $L_{\mathrm{C}}$, and width, $W_{\mathrm{C}}$, of clusters on SEM images for different samples were measured. Moreover, the circularity and the equivalent radius of inclusions were measured by using the commercial imager analysis software WinROOF ${ }^{\circledR}$. The circularity of each single inclusion/cluster was calculated as follows

$$
\mathrm{C}_{\mathrm{i}}=4 \pi \cdot \frac{\mathrm{A}_{\mathrm{i}}}{\mathrm{P}_{\mathrm{i}}^{2}}
$$

where $\mathrm{A}_{\mathrm{i}}$ and $\mathrm{P}_{\mathrm{i}}$ are the area and perimeter of the $i$-th inclusion on the SEM image determined by the WinROOF software.

Magnifications from $\times 3000$ to $\times 10000$ were used to determine the typical inclusion morphology and composition. In addition, common two-dimensional (2D) investigations on polished cross section of metal samples were performed to determine the typical inclusion composition analysis in the $\mathrm{Ti} / \mathrm{Al}$ samples by using magnification ranging from $\times 3000$ to $\times 10000$.

\section{Results and Discussions}

\subsection{Typical Morphology and Composition of Single Inclusions and Cluster}

Table 2 shows the typical non-metallic single inclusions and cluster, which were observed in the metal samples from the different deoxidation experiments. In the $\mathrm{Ti}$ deoxidation experiment (Exp. 1) only spherical single inclusions of $\mathrm{TiO}_{\mathrm{x}}-\mathrm{FeO}$ smaller than $\sim 6 \mu \mathrm{m}$ were observed. It was found that the ratio of $\mathrm{Ti} / \mathrm{Fe}$ in these inclusions is smaller than 0.18 due to the low $\mathrm{Ti}$ addition (0.03 mass\%). In the $\mathrm{Al}$ (Exp. 2) and $\mathrm{Ti} / \mathrm{Al}$ (Exp. 3) deoxidation experiments, clusters were observed in all metal samples. However, the clusters in Exp. 3 were found to be more compact than those found in Exp. 2. According to the results obtained from the $3 \mathrm{D}$ and $2 \mathrm{D}$ investigations, the inclusions in clusters in both these

Table 2. Morphology of typical single inclusions and clusters in metal samples from different deoxiation experiments.

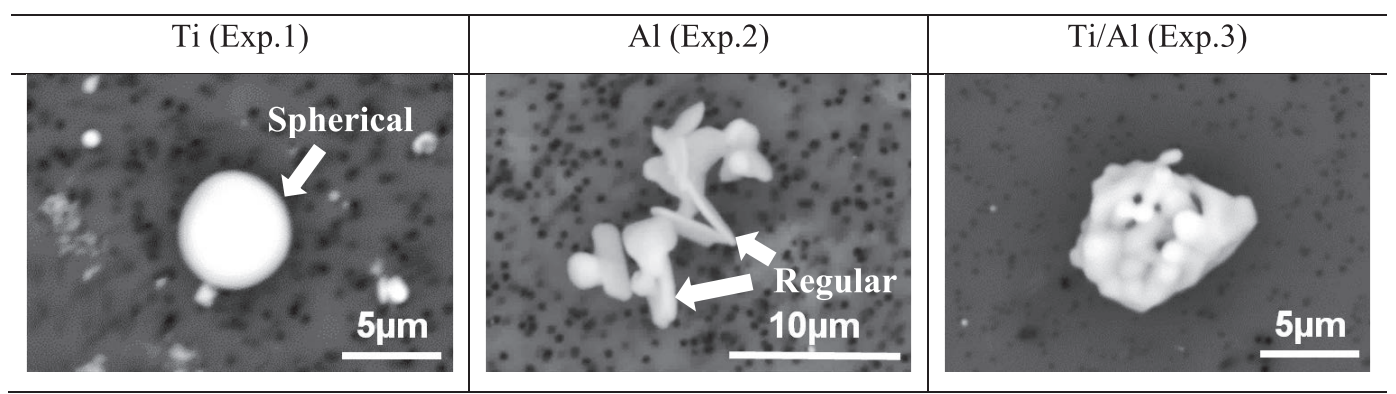


experiments (Exp. 2 and Exp. 3) were identified as pure $\mathrm{Al}_{2} \mathrm{O}_{3}$ inclusions. Thus, it was assumed that a full reduction of the initial $\mathrm{TiO}_{\mathrm{x}}-\mathrm{FeO}$ inclusions in Exp. 3 has been completed within about 1 min after an $\mathrm{Al}$ addition.

Figure 1 shows the average circularity, $C R$, of the single inclusions and clusters in the different deoxidation experiments. The error bars represent the standard deviation from the average $C R$ value. It can be seen that the $C R$ dramatically decreased from 0.86 for single spherical inclusions in Exp. 1 (Ti, holding time $1 \rightarrow 5 \mathrm{~min}$ ) to 0.58 and 0.19 for clusters in Exp. 3 (Ti/Al, holding time $1 \rightarrow 15 \mathrm{~min}$ ) and Exp. 2 (Al, holding time $1 \rightarrow 15 \mathrm{~min}$ ), respectively. It was found that the $C R$ values for clusters in the $\mathrm{Ti} / \mathrm{Al}$ experiment are about 3 times larger than those in $\mathrm{Al}$ experiment.

According to the morphology, the clustered inclusions can be divided into spherical and regular types, as shown in Table 2. Figure 2 shows the frequency of the different types of inclusions observed in the $\mathrm{Ti}, \mathrm{Ti} / \mathrm{Al}$ and $\mathrm{Al}$ deoxidation experiments. It was found that the frequency of the spherical inclusions decreased in the following order: i) $\mathrm{Ti}(100 \%)$, ii) $\mathrm{Ti} / \mathrm{Al}(69.5 \%)$ and iii) $\mathrm{Al}(34.0 \%)$.

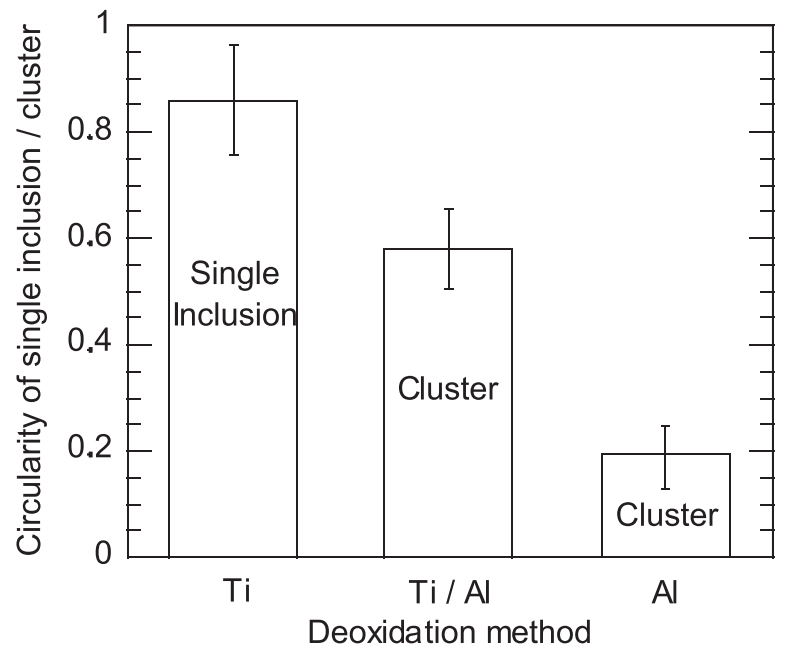

Fig. 1. Average circularity of single inclusions and clusters in samples taken after the Ti, Ti/Al and $\mathrm{Al}$ deoxidations.

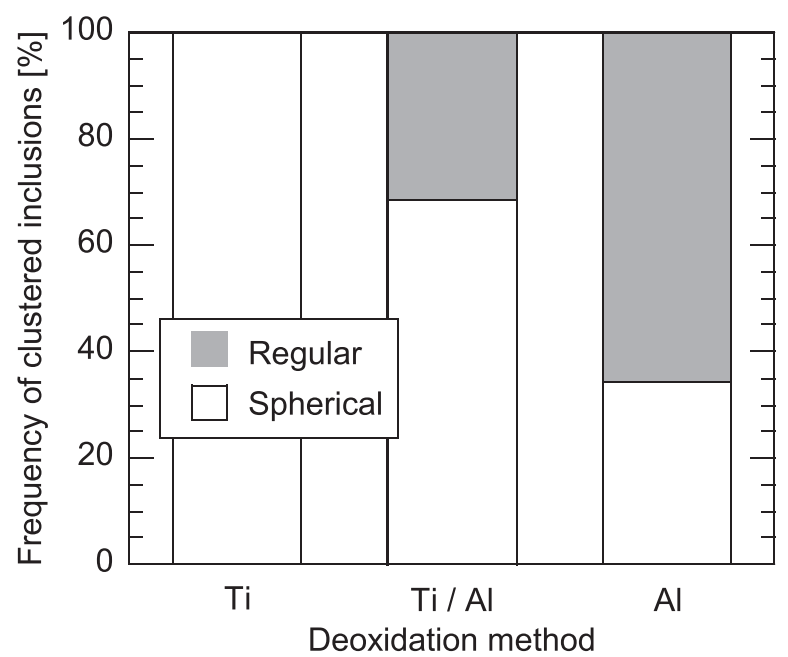

Fig. 2. Frequency of different type inclusions in $\mathrm{Ti}, \mathrm{Ti} / \mathrm{Al}$ and $\mathrm{Al}$ deoxidation experiments.

\subsection{Size Distributions of Single Inclusions and Clusters}

Figure 3 shows the single inclusion/cluster size distribution as a function of the holding time after a $\mathrm{Ti}, \mathrm{Al}$ and $\mathrm{Ti} / \mathrm{Al}$ deoxidation. In this figure the number of single inclusions, $N_{\mathrm{V}-\mathrm{I}}$, or clusters, $N_{\mathrm{V}-\mathrm{C}}$, per unit volume of metal plotted against to the diameter of spherical inclusions, $d_{\mathrm{V}-\mathrm{I}}$, in Fig. $3(\mathrm{a})$ and the average size of clusters, $d_{\mathrm{V}-\mathrm{C}}=\left(L_{\mathrm{C}}+W_{\mathrm{C}}\right) / 2$, in Figs. 3(b) and 3(c).

For the Ti deoxidation experiment shown in Fig. 3(a),

(a)
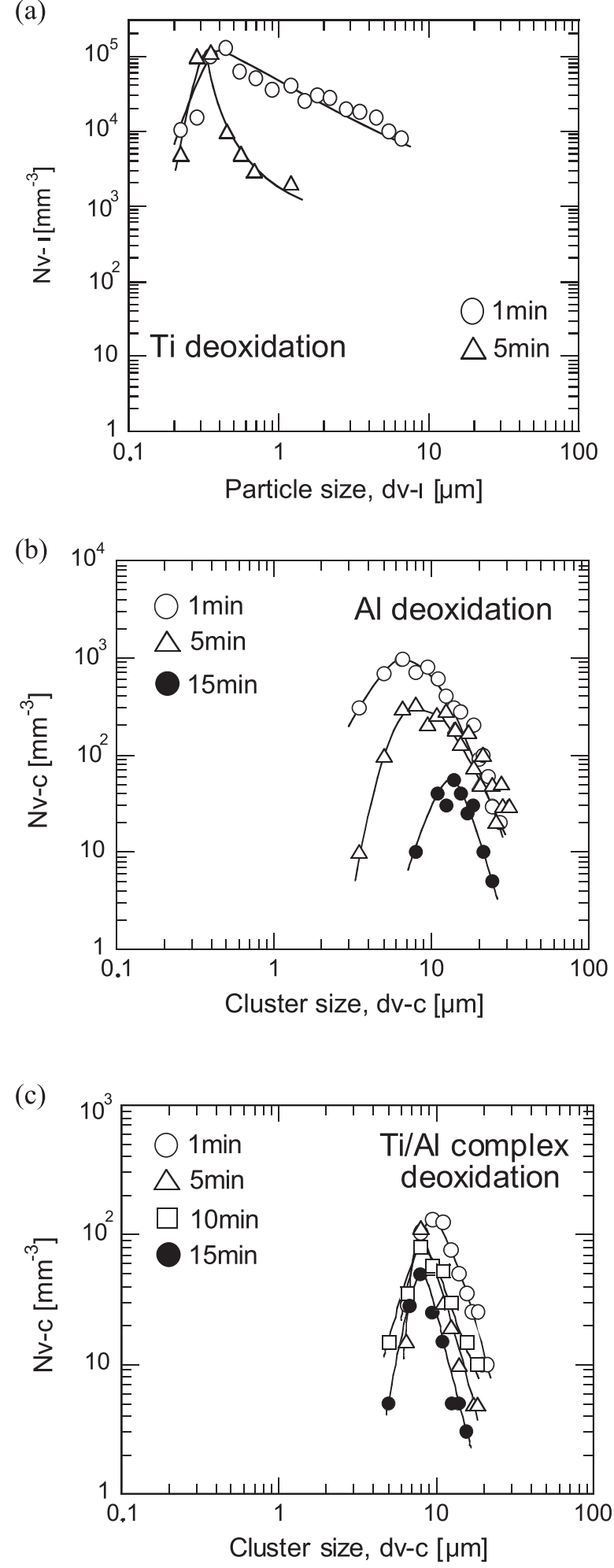

Fig. 3. Single inclusion/cluster size distribution after a deoxidation with (a) Ti, (b) Al, and (c) Ti/Al. 
the peaks of size distributions of $\mathrm{TiO}_{\mathrm{x}}-\mathrm{FeO}$ inclusions are almost same (at $d_{\mathrm{V}-\mathrm{I}} \sim 0.4 \mu \mathrm{m}$ and $N_{\mathrm{V}-\mathrm{I}} \sim 10^{5} \mathrm{~mm}^{-3}$ ). Furthermore, it can be seen that most of the single inclusions that are larger than $0.4 \mu \mathrm{m}$ have coagulated and floated out. This tendency increases with an increased holding time from 1 to $5 \mathrm{~min}$, because that the number of large sized inclusions decreases dramatically.

For the $\mathrm{Al}$ and $\mathrm{Ti} / \mathrm{Al}$ deoxidation experiments represented in Figs. 3(b) and 3(c), respectively, it was found that the peak of cluster number in the Ti/Al case $\left(N_{\mathrm{V}-\mathrm{C}} \sim 130 \mathrm{~mm}^{-3}\right)$ at a 1 min holding time is about 7 times smaller than that in the $\mathrm{Al}$ case $\left(N_{\mathrm{V}-\mathrm{C}} \sim 950 \mathrm{~mm}^{-3}\right)$. It can be seen that this difference in the $N_{\mathrm{V}-\mathrm{C}}$ peak values decreases with an increased holding time. For instance, at a $15 \mathrm{~min}$ holding time the $N_{\mathrm{V}-\mathrm{C}}$ peak for the Ti/Al case $\left(\sim 50 \mathrm{~mm}^{-3}\right)$ is only slightly smaller than that for the $\mathrm{Al}$ case $\left(\sim 55 \mathrm{~mm}^{-3}\right)$. It was found also that the peak of the cluster size in Ti/Al case $\left(d_{\mathrm{V}-\mathrm{C}} \sim 8 \mu \mathrm{m}\right)$ at a 1 min holding time is slightly larger than that in the Al case $\left(d_{\mathrm{V}-\mathrm{C}} \sim 7 \mu \mathrm{m}\right)$. The $d_{\mathrm{V}-\mathrm{C}}$ peak in the $\mathrm{Al}$ experiment increases significantly, while that in the Ti/Al experiment almost kept stable in the range between $\sim 8$ and 10 min with an increased holding time. The peak $d_{\mathrm{V}-\mathrm{C}}$ value in the $\mathrm{Al}$ experiment at a 15 min holding time is about 1.5 times larger than that in the $\mathrm{Ti} / \mathrm{Al}$ experiment. Moreover, the maximum size of the observed clusters in the Ti/Al case $(\sim 21.5 \mu \mathrm{m})$ is significantly smaller than that in the Al case $(\sim 30.5 \mu \mathrm{m})$.

Figure 4 shows a comparison of (a) the total number of the clusters per unit volume, $N_{\mathrm{V}-\mathrm{C}}$, in the metal samples and (b) the average size, $d_{\mathrm{V}-\mathrm{C}}$, of clusters in the Ti/Al and $\mathrm{Al}$ deoxidation experiments. It can be seen that the values of $N_{\mathrm{V}-\mathrm{C}}$ and $d_{\mathrm{V}-\mathrm{C}}$ in all samples from the Ti/Al deoxidation experiments are drastically smaller than the values from the Al deoxidation experiment. Moreover, the number and average size of clusters decrease significantly with an increased holding time in both experiments. So the $N_{\mathrm{V}-\mathrm{C}}$ value in the Al case with a 15 minutes holding time decreases from 5700 to $260 \mathrm{~mm}^{-3}$ ( 22 times) while that in the Ti/Al case decreases only from 550 to $150 \mathrm{~mm}^{-3}$ ( $\sim 4$ times). The decreased number of inclusions can be explained by an agglomeration of single inclusions into clusters as well as by a flotation of these large inclusions from the melt to the slag.

According to the results shown in Figs. 3 and 4, it is apparent that the formation, growth and flotation rates of clusters in the $\mathrm{Ti} / \mathrm{Al}$ deoxidation experiment are significantly smaller than those in the $\mathrm{Al}$ experiment. However, as was described above, the initial $\mathrm{TiO}_{\mathrm{x}}-\mathrm{FeO}$ inclusions in the $\mathrm{Ti} / \mathrm{Al}$ experiment were completely reduced into pure $\mathrm{Al}_{2} \mathrm{O}_{3}$ inclusions within about 1 min after an $\mathrm{Al}$ addition. As a result, the density of the inclusions in both experiments was assumed to be that of pure $\mathrm{Al}_{2} \mathrm{O}_{3}\left(=3950 \mathrm{~kg} / \mathrm{m}^{3}\right)$. In this case, the smaller number and flotation rate of clusters in the $\mathrm{Ti} / \mathrm{Al}$ experiment in comparison to the $\mathrm{Al}$ experiment cannot be explained by the difference in the densities of the formed clusters. Instead, the formation and behavior of clusters in both experiments were evaluated and compared based on consideration of collision rates of inclusions and clusters in the liquid steel.

\subsection{Collision Rates of Inclusions in $\mathrm{Al}$ and $\mathrm{Ti} / \mathrm{Al}$ Deoxi- dation Experiments}

It is well known that the collision-coalescence process among the inclusions in molten steel happens due to the following combined collisions mechanisms: 1) the Brownian collisions as a result of random movements of inclusions in the melt, $\left.\beta_{i j}^{B} ; 2\right)$ the Stokes ' collisions as a result of flotation of inclusions and clusters in the liquid steel, $\beta_{i j}^{S}$; and 3 ) turbulent collisions as a result of movement of inclusions and clusters together with melt flow $\beta_{i j}^{T}$. The total collision volume $\beta_{i j}^{T C}$ and the separate values of $\beta_{i j}^{B}, \beta_{i j}^{S}$ and $\beta_{i j}^{T}$ can be evaluated as follows: ${ }^{11-16)}$

$$
\begin{gathered}
\beta_{i j}^{T C}=\beta_{i j}^{B}+\beta_{i j}^{S}+\beta_{i j}^{T} \ldots \ldots \ldots \ldots \ldots \ldots \ldots \ldots \ldots \\
\beta_{i j}^{B}=\frac{2 k T\left(r_{i}+r_{j}\right)^{2}}{3 \mu r_{i} r_{j}} \ldots \ldots \ldots \ldots \ldots \ldots \\
\beta_{i j}^{s}=\frac{2 g \pi\left(\rho_{f}-\rho_{o x}\right)}{9 \mu}\left(r_{i}+r_{j}\right)^{3}\left|r_{i}-r_{j}\right| \ldots \\
\beta_{i j}^{T}=1.3 \alpha_{t} \sqrt{\pi \rho_{f} \varepsilon / \mu}\left(r_{i}+r_{j}\right)^{3} \ldots \ldots \ldots
\end{gathered}
$$

where $k$ is the Boltzman constant $\left(=1.3807 \times 10^{-23} \mathrm{~J} / \mathrm{K}\right), T$ is the temperature $(=1873 \mathrm{~K}), \mu$ is the dynamic viscosity of steel $(=0.006 \mathrm{~kg} / \mathrm{m} \cdot \mathrm{s})^{17)}$ and $g$ is the gravitational acceleration $\left(=9.81 \mathrm{~m} / \mathrm{s}^{2}\right)$. Moreover, $\rho_{f}$ and $\rho_{o x}$ are the densities of the liquid steel $\left(=7100 \mathrm{~kg} / \mathrm{m}^{3}\right)$ and $\mathrm{Al}_{2} \mathrm{O}_{3}$ inclusions $(=$ (a)

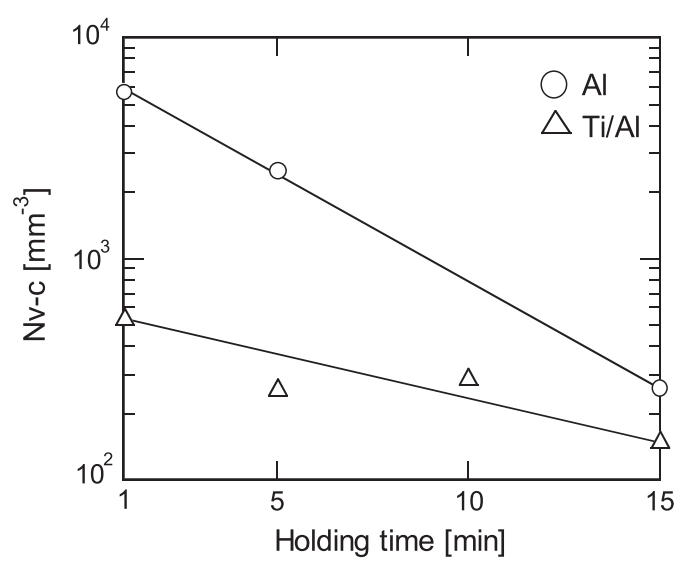

(b)

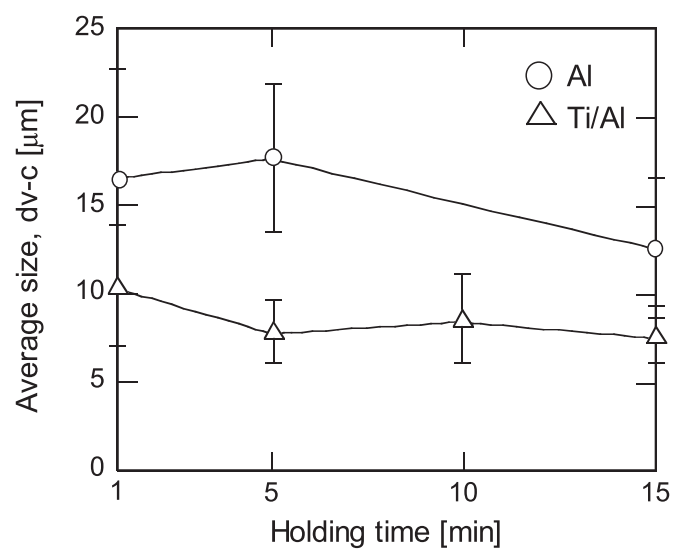

Fig. 4. Total number, $N_{\mathrm{V}-\mathrm{C}}$, and average size, $d_{\mathrm{V}-\mathrm{C}}$, of clusters in the $\mathrm{Al}$ and $\mathrm{Ti} / \mathrm{Al}$ deoxidation experiments as a function of the holding time. 
$3950 \mathrm{~kg} / \mathrm{m}^{3}$ ), respectively. The parameter $\alpha_{t}$ is the agglomeration coefficient, $\varepsilon$ is the turbulent energy dissipation rate $\left.\left(=0.01 \mathrm{~m}^{2} / \mathrm{s}^{3}\right) .{ }^{17}\right) r_{i}$ and $r_{j}$ are the radii of the two colliding inclusions.

The value of the agglomeration coefficient, $\alpha_{t}$, can be obtained by using the following equation: ${ }^{18,19)}$

$$
\alpha_{t}=0.727\left[\frac{\mu r_{i}^{3}\left(\rho_{f} \varepsilon / \mu\right)^{1 / 2}}{A_{121}}\right]^{-0.242} / \sqrt{\pi}
$$

where $A_{121}$ is the Hamaker constant for $\mathrm{Al}_{2} \mathrm{O}_{3}$ in liquid iron $\left(=14.3 \times 10^{-19} \mathrm{~J}\right){ }^{20)}$

The collision rate of the inclusions in the melt can be evaluated as follows: $:^{21)}$

$$
\frac{d n_{i j}}{d t}=\beta_{i j}^{T C} n_{i} n_{j}
$$

where $n_{i}$ and $n_{j}$ are the numbers of the colliding inclusions with radii $r_{i}$ and $r_{j}$, respectively. $t$ is the time [s].

In this study, it was assumed that the formation of the cluster occurs mainly due to the collisions of the particleparticle (P-P) in the clusters, particle-cluster (P-C) and cluster-cluster $(\mathrm{C}-\mathrm{C})$. Figure $\mathbf{5}$ shows the particle size distributions of inclusions in all observed clusters in the $\mathrm{Al}$ and Ti/Al deoxidation experiments depending on holding time. In this case, the particle size for each inclusion in a cluster, $d_{\mathrm{V}-\mathrm{PC}}$, was determined as the equivalent diameter of a circle having the same area as the inclusion found on the SEM image by using the $\mathrm{WinROOF}^{\circledR}$ software. It can be seen that the size of inclusions in clusters increased significantly in both experiments.

For evaluation of the $\alpha_{t}$ values by using Eq. (6) at different holding times in the $\mathrm{Al}$ and $\mathrm{Ti} / \mathrm{Al}$ experiments, the values of $r_{i}$ corresponds to the $0.5 \cdot d_{\mathrm{V}-\mathrm{PC}}$ for the peak size in each size distribution curve in Fig. 5 were used. The $r_{i}$ and $\alpha_{t}$ values are summarized in Table 3 . The selected values of $n_{i}$ and $n_{j}$ in Eq. (7) correspond to the $N_{\mathrm{V}-\mathrm{PC}}$ values for the clustered inclusions having the radii of $r_{i}$ and $r_{j}$ in the size distribution. The total collision rate between particle-particle in clusters, $C R_{(\mathrm{P}-\mathrm{P})}$, was calculated by using Eqs. (2)-(7). The total collision rates between particle-cluster, $C R_{(\mathrm{P}-\mathrm{C})}$, and cluster-cluster, $C R_{(\mathrm{C}-\mathrm{C})}$, were calculated in similar man- ner. Figure 6 shows the values of $C R_{(\mathrm{P}-\mathrm{P})}, C R_{(\mathrm{P}-\mathrm{C})}$ and $C R_{(\mathrm{C}-\mathrm{C})}$ obtained for $\mathrm{Al}$ and a $\mathrm{Ti} / \mathrm{Al}$ deoxidation experiments as a function of the holding time. It is apparent that the formation and growth rates of clusters in the Al deoxidation experiment are significantly larger in comparison to those

Table 3. Agglomeration coefficients for an Al deoxidation and a Ti/Al deoxidation experiment.

\begin{tabular}{cccccc}
\hline \multirow{2}{*}{ Deoxidation } & $\begin{array}{c}\text { Holding time } \\
{[\mathrm{min}]}\end{array}$ & \multicolumn{2}{c}{$\begin{array}{c}\text { Collision of P-P } \\
\text { and P-C }\end{array}$} & \multicolumn{2}{c}{ Collision of C-C } \\
\cline { 3 - 6 } & 1 & 0.75 & 0.61 & 3.3 & 0.21 \\
\hline $\mathrm{A} 1$ & 5 & 0.85 & 0.56 & 4.0 & 0.18 \\
& 15 & 1.05 & 0.48 & 7.0 & 0.12 \\
\hline \multirow{2}{*}{ Ti/Al } & 1 & 0.55 & 0.77 & 4.8 & 0.16 \\
& 5 & 0.75 & 0.61 & 4.0 & 0.18 \\
& 10 & 0.75 & 0.61 & 4.0 & 0.18 \\
& 15 & 0.95 & 0.51 & 4.0 & 0.18 \\
\hline
\end{tabular}

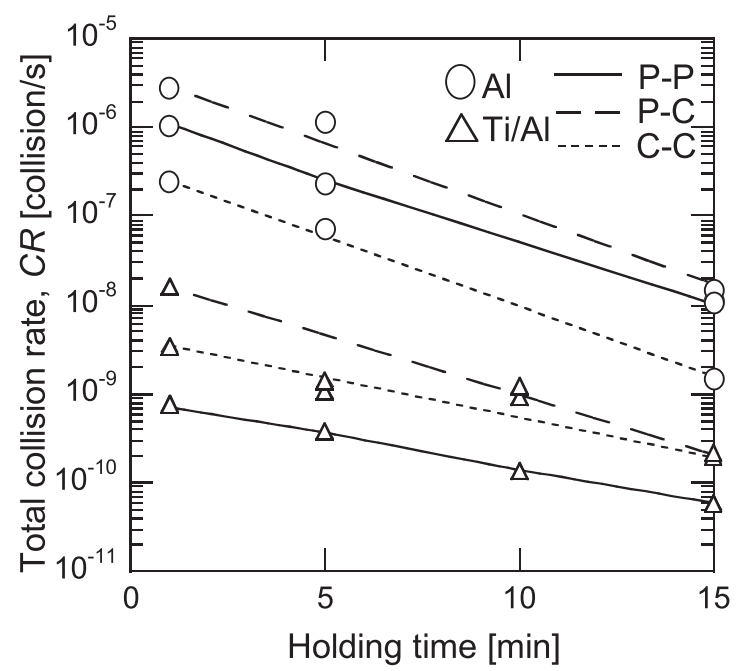

Fig. 6. Total collision rates between particle-particle in clusters, $C R_{(\mathrm{P}-\mathrm{P})}$, particle-cluster, $C R_{(\mathrm{P}-\mathrm{C})}$, and cluster-cluster, $C R_{(\mathrm{C}-\mathrm{C})}$, in $\mathrm{Al}$ and $\mathrm{Ti} / \mathrm{Al}$ experiments as a function of the holding time.
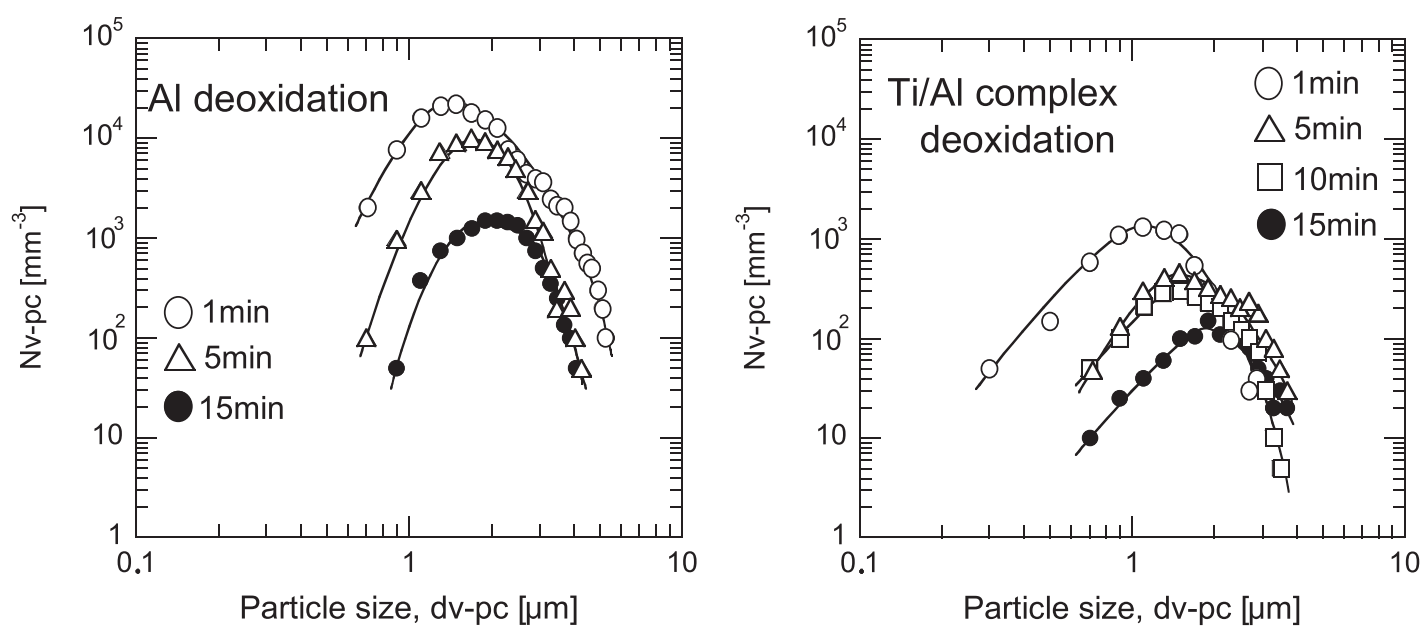

Fig. 5. Particle size distributions of inclusions in the observed clusters in $\mathrm{Al}$ (a) and $\mathrm{Ti} / \mathrm{Al}$ (b) deoxidation experiments depending on holding time. 
in the Ti/Al deoxidation experiment. This is due to the larger values of the total collision rates. So the values of $C R_{(\mathrm{P}-\mathrm{P})}, C R_{(\mathrm{P}-\mathrm{C})}$ and $C R_{(\mathrm{C}-\mathrm{C})}$ in the $\mathrm{Ti} / \mathrm{Al}$ experiment at $1 \mathrm{~min}$ of holding time are about 1400,170 and 70 times smaller than those in the $\mathrm{Al}$ experiment. However, the difference between these total collisions rates in both experiments decrease with an increased holding time. As a result, the $C R_{(\mathrm{Al})} / C R_{(\mathrm{Ti} / \mathrm{Al})}$ ratio at $15 \mathrm{~min}$ of holding time decreases respectively by up to about 180,65 and 7 times compared to their initial values.

It is interesting to point out that the Brownian collisions have no practically effect on the formation and growth of clusters because the values of $\beta_{i j}^{B}$ for inclusions and clusters in both experiments varied mostly between 0.01 and $3.0 \%$ of the total collision volume value. The turbulent collision ( $\left.\beta_{i j}^{T} \sim 51-93 \%\right)$ and Stokes' collision $\left(\beta_{i j}^{S} \sim 6-48 \%\right)$ are the main reasons for a formation and growth of clusters in the $\mathrm{Al}$ and $\mathrm{Ti} / \mathrm{Al}$ experiments. Moreover, it was found that the $\beta_{i j}^{S}$ values for particle-cluster and cluster-cluster collisions are significantly larger in the $\mathrm{Al}$ experiment than those in the $\mathrm{Ti} / \mathrm{Al}$ experiment. It may be explained by the larger size of clusters and, as a result due to the larger the Stokes' collisions in the $\mathrm{Al}$ experiment in comparison to the $\mathrm{Ti} / \mathrm{Al}$ experiment.

\section{Conclusion}

The characteristics of non-metallic single inclusions and clusters produced by a complex $\mathrm{Ti} / \mathrm{Al}$ deoxidation of a Fe-10 mass\%Ni alloy were investigated and compared to the data from the $\mathrm{Ti}$ and $\mathrm{Al}$ deoxidation experiments. Agglomeration mechanism and collision rates of inclusions were considered in the $\mathrm{Al}$ and $\mathrm{Ti} / \mathrm{Al}$ deoxidation experiments. Based on the results from the study, the following important conclusion can be made:

- The average circularity of clusters, $\mathrm{C}_{\mathrm{i}}$, which is a quantitative characteristic of the cluster morphology, is about 3 times larger in the Ti/Al experiment than in the $\mathrm{Al}$ experiment. It means that the clusters in the Ti/Al experiment are more compact than those in the $\mathrm{Al}$ experiment.

- The number, $N_{\mathrm{V}-\mathrm{C}}$, and average size, $d_{\mathrm{V}-\mathrm{C}}$, of clusters in all samples of the Ti/Al deoxidation experiment are drastically smaller (about 11-2 times for $N_{\mathrm{V}-\mathrm{C}}$ and 1.6-2.2 times for $d_{\mathrm{V}-\mathrm{C}}$ ) than those in the $\mathrm{Al}$ deoxidation experiment. However, the number and average size of clusters decreased significantly with an increased holding time in both experi- ments, due to the agglomeration and flotation of the formed clusters.

- Evaluated total collision rates between particle-particle in clusters, $C R_{(\mathrm{P}-\mathrm{P})}$, particle-cluster, $C R_{(\mathrm{P}-\mathrm{C})}$, and clustercluster, $C R_{(\mathrm{C}-\mathrm{C})}$, in the Ti/Al experiment at $1 \mathrm{~min}$ of holding time are about 1400,170 and 70 times smaller than those in the $\mathrm{Al}$ experiment. However, this difference decreased significantly with an increased holding time up to $\sim 180,65$ and 7 times at a 15 min holding time.

- Turbulent and Stokes`collisions are the major factors causing a formation and growth of clusters in the $\mathrm{Al}$ and $\mathrm{Ti} / \mathrm{Al}$ experiments. Specifically, the turbulent and Stokes' collision volumes ( $\beta_{i j}^{T}$ and $\beta_{i j}^{S}$ ) correspond to $\sim 51-93 \%$ and $\sim 6-48 \%$ of the total collision volume, respectively.

\section{Acknowledgement}

The authors would like to acknowledge KTH Royal Institute of Technology for financial support.

\section{REFERENCES}

1) H. Matsuura, C. Wang, G.-H. Wen and S. Sridhar: ISIJ Int., 47 (2007), 1265 .

2) C. Wang, N. Verma, Y. Kwon, W. Tiekink, N. Kikuchi and S. Sridhar: ISIJ Int., 51 (2011), 375.

3) C. Wang, N. T. Nufher and S. Sridhar: Metall. Mater. Trans. B, 40 (2009), 1005.

4) C. Wang, N. T. Nufher and S. Sridhar: Metall. Mater. Trans. B, 40 (2009), 1022.

5) M.-K. Sun, I.-H. Jung and H.-G. Lee: Metall. Mater. Int., 14 (2008), 791.

6) A. V. Karasev, C.-J. Xuan, R. Inoue and P. G. Jönsson: Proc. 8th Int. Conf. Clean Steel, Hungarian Mining and Metallurgical Society, Budapest, Hungary, (2012).

7) I.-H. Jung, S. Decterov and A. D. Pelton: ISIJ Int., 44 (2004), 527.

8) S. A. Decterov, I.-H. Jung, E. Jak, Y.-B. Kang, P. Hayes and A. D. Pelton: Proc. 7th Int. Conf. Molten Slags, Fluxes and Salts, South African Inst. Min. Met, Johannesburg, (2004), 839.

9) F. Ruby-Meyer, J. Lehmann and H. Gaye: Scand, J. Metall., 29 (2000), 206.

10) W. Choi, H. Matsuura and F. Tsukihashi: ISIJ Int., 51 (2011), 1951.

11) Y. Miki, Y. Shimada, B. G. Thomas and A. Denisor: Iron Steelmaker, 24 (1997), 31.

12) L. Zhang, S. Taniguchi and K. Cai: Metall. Mater. Trans. B, 31B (2000), 253.

13) H. Lei, G. Xu and J. He: Chem. Eng. Technol., 30 (2007), 1650.

14) H. Lei and J. He: J. Non-Cryst. Solids, 352 (2006), 3772.

15) L. Zhang and W. Pluschkell: Ironmaking Steelmaking, 30 (2003), 106.

16) J. Zhang and H. Lee: ISIJ Int., 44 (2004), 1629.

17) K. Nakanishi and J. Szekely: Trans. Iron Steel Inst. Jpn., 15 (1975), 522.

18) T. Nakaoka, S. Taniguchi, K. Matsumoto and S. T. Johansen: ISIJ Int., 41 (2001), 1103.

19) H. Lei, K. Nakajima and J.-C. He: ISIJ Int., 50 (2010), 1735

20) C.-J. Xuan, A. V. Karasev, P. G. Jönsson and K. Nakajima: Steel Res. Int., 87 (2016), DOI: 10.1002/sirn.201600090.

21) M. Nabeel, A. Karasev and P. G. Jönsson: ISIJ Int., 55 (2015), 2358. 